Revue d'histoire de l'Amérique française

REVUE D.HISTOIRE DE L'AMÉRIQUE FRANÇAISE

\title{
KURGAN-VAN HENTENRYK, G. et J. LAUREYSSENS, Un siècle d'investissements belges au Canada. Bruxelles, Éditions de l'Université de Bruxelles, Centre d'études canadiennes de l’Université Libre de Bruxelles, 1986. 152 p. 795 FB
}

\section{Marc Vallières}

Volume 41, numéro 2, automne 1987

URI : https://id.erudit.org/iderudit/304566ar

DOI : https://doi.org/10.7202/304566ar

Aller au sommaire du numéro

Éditeur(s)

Institut d'histoire de l'Amérique française

ISSN

0035-2357 (imprimé)

1492-1383 (numérique)

Découvrir la revue

Citer ce compte rendu

Vallières, M. (1987). Compte rendu de [KURGAN-VAN HENTENRYK, G. et J. LAUREYSSENS, Un siècle d'investissements belges au Canada. Bruxelles, Éditions de l'Université de Bruxelles, Centre d'études canadiennes de l'Université Libre de Bruxelles, 1986. 152 p. 795 FB]. Revue d'histoire de l'Amérique française, 41(2), 271-273. https://doi.org/10.7202/304566ar d'utilisation que vous pouvez consulter en ligne. 
KURGAN-VAN HENTENRYK, G. et J. LAUREYSSENS, Un siècle d' investissements belges au Canada. Bruxelles, Éditions de l'Université de Bruxelles, Centre d'études canadiennes de l'Université Libre de Bruxelles, 1986. 152 p. 795 FB

Ce petit livre constitue le fruit d'une collaboration entre le Centre d'études canadiennes de 1'Université Libre de Bruxelles et la professeure Julie Laureyssens de l'Université du Manitoba. Il présente un survol rapide de l'histoire 
des investissements belges au Canada et une courte monographie sur l'une des sociétés belges les plus actives au Canada, la Genstar.

Dans une première partie de l'ouvrage, la professeure Ginette KurganVan Hentenryk dresse une synthèse rapide des activités d'investissements belges au Canada jusqu'à la Seconde Guerre mondiale. Elle s'appuie sur une exploration des archives du ministère belge des Affaires étrangères (notamment les archives consulaires) et des périodiques belges d'information boursière et financière, sur un éventail de monographies et aussi sur des travaux et des études de chercheurs québécois, en particulier sur les compagnies papetières (notamment sur la Belgo-Canadian Pulp and Paper).

Il ressort qu'au 19e siècle, ces investissements demeurent exceptionnels, mais que, entre 1900 et 1913 , ils connaissent une expansion marquée - à l'instigation, surtout, de la Banque d'Outremer - et concentrée dans l'exploitation des richesses naturelles, soit les pâtes et papier en Mauricie et les charbonnages en Nouvelle-Écosse. Un second groupe de financiers, des Anversois, se lancent dans des placements immobiliers, ruraux et urbains, principalement dans l'Ouest canadien. Dans l'entre-deux-guerres toutefois, cette pénétration s'arrête presque complètement et on assiste même au retrait ou à l'absorption des investissements dans les pâtes et papier, dès les années 1920.

Dans la seconde partie de l'ouvrage, la professeure Laureyssens met en relief le redémarrage de ces investissements dans les années 1950 sous l'impulsion des grands holdings à vocation multi-industrielle et multinationale. Les investissements s'orientent nettement vers l'industrie lourde, celle des biens d'équipement, les transports et les services publics. La Société Générale de Belgique arrive en 1951 et constituera le pivot des intérêts miniers (Sogémines et Genstar). S'ajoutent, à partir de 1953, dans le secteur énergétique, la Canadian Petrofina et la Canadian Hydrocarbons. Cette dernière entreprise est liée au groupe Empain qui s'intéresse aussi à l'immobilier (Candiac Development Corp.). On les retrouve dans le ciment (Miron), dans le verre (Glaverbel), dans les matériaux de fondation (Franki), dans les armes (F. N. Herstal) et dans le transport maritime (Dart Containers). L'auteure décrit également le reflux qui s'amorce à la fin des années 1970 , notamment par l'achat controversé (p. 88-89) de Canadian Petrofina par le gouvernement fédéral et sa transformation en Petro-Canada. Cette seconde partie, plus technique, se fonde sur des données de Statistique Canada montrant les ramifications dans le contrôle des firmes et sur les rapports annuels des entreprises impliquées. Malgré l'intérêt factuel du contenu, les sources consultées ne se prêtaient pas spécialement à un approfondissement des stratégies dans la continuité de la première partie et le lecteur reste un peu sur sa faim.

Dans la troisième partie, la professeure Laureyssens a choisi l'exemple de Sogémines-Genstar pour décortiquer la dynamique de contrôle et d'investissements d'une société qui a connu un succès important au Canada. En élargissant son éventail documentaire aux journaux et aux périodiques financiers, l'auteure nous fait pénétrer plus concrètement dans les recoins subtils des contrôles indirects, cachés derrière des Conseils d'administration formés d' «autochtones». Elle fait ressortir aussi comment l'implantation au Canada constitue souvent la porte d'entrée sur l'ensemble du marché nord-américain. 
Elle montre également les effets de la FIRA et de son examen des investissements étrangers sur les modalités de contrôle utilisées par les maisons-mères.

Malgré certaines limites qui tiennent en partie à la formule d'édition (les deux contributions se suivent par le thème et la chronologie, mais se différencient par les sources et, partant, par le résultat), il s'agit d'une contribution monographique très intéressante. Ce lecteur aurait peut-être souhaité une meilleure remise en contexte ou un approfondissement de la période de l'aprèsguerre ou encore un développement du cas Petrofina, mais il a tout de même très apprécié ce qu'il a lu.

Département d' histoire 